\title{
Criatividade e Protagonismo Indígenas
}

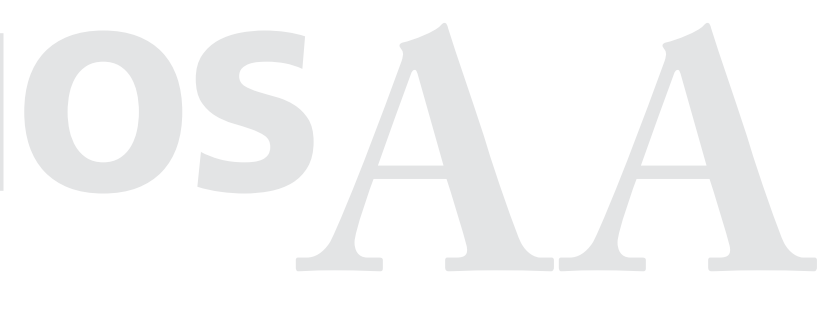

Maria Rosário de Carvalho ${ }^{1}$

Universidade Federal da Bahia

dossiê deste Vol. 3 No. 2(2013) tem como autores cinco jovens, três dos quais indígero, predominantemente no município de Palmeira dos Indios, agreste alagoano, e um pequeno contingente no muncípio de Glória, no estado da Bahia) e um do povo Pataxó, hoje distribuído em várias aldeias na porção do extremo-sul baiano e no estado de Minas Gerais; e dois jovens não índios. Os três primeiros tomam como objetos de reflexão, respectivamente, o processo de criação da política indigenista no estado da Bahia; o modelo de gestão territorializada da política de educação escolar indígena nesse mesmo estado; e a produção, consumo e circulação dos adornos pataxós, mediante um exercício de imersão na cultura da autora, ao passo que os dois não índios examinam uma performance ritual criada e encenada por jovens índios Xokó do município de Porto da Folha, estado de Sergipe, no baixo curso do rio São Francisco; e a formação de uma nova aldeia pataxó que viria a se tornar uma espécie de laboratório para a cultura nativa.

$\mathrm{Na}$ chamada para o Dosssiê, enfatizamos que o tema "Criatividade e Protagonismo Indígenas" deveria se apresentar em distintos contextos etnográficos e diversas abordagens teóricas e metodológicas. A nossa expectativa era, então, a de que os textos submetidos tratassem o tema por meio de expressões individuais e coletivas e recortes múltiplos, permitindo ao leitor surpreender o seu potencial tarnsformador no plano das relações sociais e políticas, internas e externas às sociedades indígenas. A nossa intenção, nesta Introdução, é, pois, avaliar até que ponto essa expectativa foi concretizada, e como o foi.

O título do artigo de Arissana Braz Bomfim - a aranha vive do que tece --, uma clara alusão aos aracnídeos que segregam seda, com a qual tecem as suas teias -- e o seu primeiro subtítulo "Pra gente nunca esquecer o que nossos pais deixaro" talvez possam ser entendidos, combinadamente, como a expressão sintética do ethos da trajetória de uma indígena pataxó que, desde muito jovem, passou a colaborar, efetivamente, para assegurar a reprodução biológica e social da sua família de orientação, assim como teriam procedido os seus pais, avós e ascenden-

1 Professora Associada do Departamento de Antropologia da Faculdade de Filosofia e Ciências Humanas da Universidade Federal da Bahia. 
tes genealogicamente mais distantes. Esse legado ético-moral constitui um valor a ser cultivado e transmitido às novas gerações -- como a da sua filhinha Atxinãe - e uma fonte de inspiração permanente para uma vida autêntica, no sentido de autônoma e criativa.

Sem parentes e sem a contínua renovação daquela considerada como 'a tradição' pataxó, material e simbólica, parece não haver condições efetivas de vida para esse povo. Os adereços compõem parte significativa dessa tradição que, a partir dos anos 1970, também se destinam ao mercado regional, como item crescentemente relevante para a geração de renda monetária necessária à aquisição dos produtos industrializados. Mas o seu valor estético não decresceu. Ao se adornarem com os colares, cocares, tangas, pentes, pulseiras e etc, os vendedores pataxós exibem, simultaneamente, os seus produtos artesanais e a sua identidade étnica, em uma relação de imbricação que propicia à última agregar valor aos primeiros. Entre as crianças, particularmente, a colaboração na produção e venda desses objetos ornamentais funciona como atividade produtiva e identitária. Nesse sentido, a produção e circulação dos adereços parece funcionar como uma estratégia de emulação intraétnica e interétnica e, ademais, como uma fonte de inserção econômica ponderável, notadamente para algumas aldeias cujo ingresso monetário quase exclusivo provém da atividade artesanal.

Por outro lado, suponho constituir evidência de que a atividade artesanal não é praticada apenas como motivação econômica o fato das novas ocupações, decorrentes do processo de escolarização formal, tais como de professores e coordenadores de grupos de cultura, não terem suscitado o seu abandono. Para eles, a elaboração dos adereços indígenas deve estar sendo entendida como uma atividade cultural fundamental para o exercício das suas novas ocupações e não apenas uma atividade manual que requer certa habilidade. Mas pode constituir, complementarmente, e desse modo ser apreendida, como uma expressão artística da qual usufruem prazer estético, como evidencia a maior elaboração dos colares, e outros itens, usados para adornar os corpos indígenas em dias especiais.

Arissana Braz afirma que "aprender a fazer os adereços é um dos primeiros passos de um processo de constituição da arte Pataxó”. Arte que pode ser considerada mais abrangente, para dar lugar, por exemplo, às armadilhas de caça que eu, no já longínquo ano de 1976, busquei, sistematicamente, desenhar em meus cadernos de campo, tal a atração que exerciam sobre mim tais artefatos que, engenhosamente, adaptavam-se perfeitamente ao ambiente, condição indispensável para a sua eficácia. Alfred Gell, com sensibilidade quase poética, ao explorar a base de distinção comumente empregada entre trabalhos de arte ou objetos de arte, e 'meros' artefatos - úteis mas não esteticamente interessantes ou belos --, busca demonstrar - problematizando as teorias institucional e interpretativa de arte elaboradas pelo filósofo Arthur Danto -- que as armadilhas animais poderiam, muito bem, ser exibidas como arte, "porque elas tendem a incorporar ideias e intenções complexas relativas às relações entre homens e animais, e porque elas provêm um modelo do próprio caçador e da sua ideia do mundo da presa animal" ${ }^{2}$, em face do que ele concluirá que uma definição aestética do objeto de arte é, consequentemente, insatisfatória” (Gell, 1996, p. 15). Os úteis, e igualmente belos, adereços Pataxó são, pois, bons exemplos da arte Pataxó, como o são as miniaturas de animais habilmente esculpidas em madeira por Ananias Nascimento e as armadilhas para caça já mencionadas.

2 Cada armadilha não é apenas um modelo do seu criador mas um self subsidiário sob a forma de um autômato, mas também um modelo de sua vítima. (...) De acordo com a forma da armadilha, as disposições da pretendida vítima podem ser deduzidas. Neste sentido, armadilhas podem ser consideradas textos do comportamento animal (Gell, 1996, p. 27) 
Finalmente, quero referir ainda, no que concerne ao artigo de Arissana, ao uso das penas de galinha e matérias primas industrializadas. Em um caso e outro, não há, por parte dos produtores - e a autora é, também, produtora --, pejo em admitir o seu uso. Há, vale lembrar, excelentes antecedentes de tais usos sem pejo aparente. Estou referindo aos famosos mantos Tupinambá. Mais particularmente ao manto depositado no Museu da Dinamarca, no qual um estudo realizado na Holanda, em 1979, teria identificado a presença de penas de galinha ("chicken down") ${ }^{3}$. Felipe Vander Velden Ferreira registra, por sua vez, que o manto Tupinambá guardado no Museu do Homem, em Paris, contém, em sua extremidade superior, uma tira de miçangas azuis e brancas de origem europeia (Métraux, 1932, p. 4 apud Ferreira, p. 32, nota 8). Ferreira indaga, argutamente, se esses mantos com penas de galinha teriam sido confeccionados para uso ritual ou terão sido simples "peças decorativas, circulando em uma rede crescente de peças provenientes de populações primitivas, e trazidas de cantos remotos do globo para o espanto e a admiração dos europeus? Tais artefatos dirão mais sobre os Tupi litorâneos ou sobre os europeus que deles adquiriam as peças guardadas ciosamente por uns poucos museus na Europa?” (Ferreira, 2012, p. 100-101).

Ora, admitindo-se que, já nos séculos XVI e XVII, os Tupinambá na costa brasileira coloriam artificialmente penas de galinhas para a confecção dos seus mantos, "qual é a razão para considerarmos, hoje, como espúrio ou inautêntico, o uso das penas destas aves nos adornos plumários e outros objetos de certas populações indígenas (...)?” (Ferreira, 2012, p. 7).

No artigo "Aldeia Velha, "nova na cultura": reconstituição territorial e novos espaços de protagonismo entre os Pataxó", Hugo Prudente Pedreira demonstra que tais novos espaços resultaram de uma forte mobilização pela recuperação de áreas expropriadas aos Pataxó, no âmbito da qual certos agentes sociais se destacam e, na sucessão dos acontecimentos, têm a sua liderança contestada e destituída. Uma certa tendência à centralização do poder então enfeixado costuma ocorrer e confronta-se com a resistência dos liderados, aparentemente predispostos à renovação desse poder em cadeia ou rede (e não apropriável como uma riqueza ou um bem), em cujas malhas "os indivíduos não só circulam mas estão sempre em posição de exercer este poder e de sofrer sua ação; nunca são o alvo inerte ou consentido do poder, são sempre centros de transmissão" (Foucault, 1986, p. 183-184). Nesse sentido, o leitor poderá acompanhar, em escala reduzida, a constituição de grupos, líderes e unidades políticas, assim como os mecanismos que são acionados para opor obstáculos à sua estabilização e ao enrijecimento de assimetrias (Sztutman, 2008) na Aldeia Velha.

3 O tema foi objeto de uma troca de e-mail's, em 2005, entre John Monteiro e Amy J. Buono, do Departamento de História da Arte \& Arquitetura da Universidade da Califórnia, Santa Barbara. Monteiro supunha que o estudo, que teria identificado penas de galinhas no manto depositado no Museu da Dinamarca, referido por Buono, faria parte do livro organizado por Ernst avan den Boogaart, Johan Maurits van Nassau Siegen, 1604-1679, A humanist prince in Europe and Brazil. Haia: Government Publishing Office, 1979. Para Monteiro, o príncipe Nassau teria recebido o manto de um dos líderes Potiguar que ele incorporou à sua corte, em Recife/PE, algum tempo antes de retornar a Holanda, em 1644. Monteiro demonstrava curiosidade em saber quando o referido manto teria sido identificado como Tupinambá, ao tempo que observava que os holandeses designavam os falantes Tupi simplesmente Brasilianer, em oposição aos Tapuia, não Tupi (a cópia da troca de e-mail's foi redirecionada, generosamente, por J. Monteiro para Patrícia Couto, pesquisadora do Programa de Pesquisas sobre Povos Indígenas do Nordeste Brasileiro da UFBA que, por sua vez, o compartilhou comigo). Vale registrar que o assunto tratado nesse e-mail pode ter sido suscitado pelo livro de Berete Due (2002) que, além de reproduzir as peças plumárias da Kunstkammer Real, observa que a peça Hc.52 inclui, possivelmente, penas tingidas de galinha (apud Ferreira 2012, p. 32, nota 7). 
Designa-se de retomada às ações que, nos contextos etnográficos nordeste e leste do Brasil, buscam reintegrar aos territórios tradicionais parcelas que, ao longo dos anos, deles foram expropriadas. Em geral as retomadas envolvem homens, mulheres e crianças que, em ações concertadas, recuperam-nas e mantêm-nas sob a sua posse, acionando, na sequência, o Ministério Público Federal para que este interponha ação de reintegração de posse e a cassacão de liminares de reintegração contrapostas pelos comumente designados fazendeiros. Via de regra as liminares são prontamente acolhidas pelos juízes locais, o que leva, muitas vezes, o contingente indígena ameaçado de expulsão da parcela retomada a resistir ao seu cumprimento por agentes da polícia militar. Exitosa a resistência, recursos e apoios, materiais e políticos, são mobilizados para viabilizar a retomada e desencadear o processo de regularização junto à FUNAI. Na sequência são realizados os estudos de identificação da área que, concluídos, são apreciados pelo Ministério da Justiça.

No caso da Aldeia Velha, doze anos de muitas lutas transcorreram entre as primeiras ações de retomada e a definitiva, em 1998, que ensejou a abertura do já referido processo de regularização. Ao longo desses anos a comunidade indígena foi sendo formada, compelida a sobreviver sob barracas de plástico, liderada pelo que viria a se tornar o cacique Ipê, pelo Conselho de Caciques Pataxó e por Dona Dió, reconhecida como a única indígena que jamais se deslocou da Aldeia Velha. Como bem observa Pedreira, a comunidade política antecedeu a conquista, e organização, do território.

O consenso positivo construído em torno da liderança de Ipê e fortemente apoiado no valor advindo do trabalho por ele desenvolvido, não foi suficiente para mantê-lo no cargo de cacique: restrições à sua forma de atuação isolacionista, combinadas a outros fatores, retraíram os seus liderados que, em uma consulta participativa, optaram pelo candidato concorrente.

Velha em termos de existência e "nova na cultura": é assim que os Pataxó a consideram, aludindo ao antigo aldeamento Santo Amaro do qual se originou, estabelecido no século XVI e extinto em data não definida. Prospecções arqueológicas realizadas na Terra Indígena Aldeia Velha por uma equipe coordenada pelo arqueólogo Carlos Etchevane, da UFBA, localizou seis sítios, pré-coloniais e pós-coloniais, caracterizados como de ocupação indígena (Pedreira, 2013, p. 8). Dos mais jovens, em larga medida escolarizados e com maior domínio sobre as instâncias burocrático-institucionais, se espera que contribuam para o desenvolvimento da cultura nativa, inserindo-a no circuito do território pataxó tal como compreendido pelo conjunto descontínuo das suas aldeias estabelecidas no estado da Bahia, e a transformem em uma estratégia de comunicação intercultural, sob a mediação do parentesco, e de percepção crítica da ordem social, regional e nacional, onde estão imersos.

Os jovens Xokó de Porto da Folha, no estado de Sergipe, engajam-se também política e culturalmente, mas o fazem apelando para a dramatização cênica de uma história de violência que vivenciaram, em parte, enquanto crianças, mas que predominantemente ouviram dos parentes mais velhos. A dramatização parece facultar-lhes rememorar os fatos de acordo com uma leitura na qual emergem como autores e atores e não como a parte vilipendiada, o que parece contribuir para mitigar a sua dor (ação reparadora, no modelo de drama social elaborado por Victor Turner, que, vale notar, não é utilizado por Natelson Souza (Dawsey, 2005, p. 165), re- 
cuperar certa segurança ontológica e reforçar a sua identidade étnica ${ }^{4}$. Em outras termos, uma estratégia de ressignificação do mundo, da qual participam também não índios que se apresentam como interessados em sua causa e que são "criativamente incorporados como personagens interpretados pelos próprios indígenas"

Finalmente, os artigos "O modelo de gestão territorializada da política de educação escolar indígena no estado da Bahia" " "Processos de criação da política indigenista no estado da Bahia: atores e arranjos institucionais", tratam, respectivamente, da educação intercultural no estado da Bahia, a partir da análise do novo modelo de gestão definido como Território Etnoeducacional; e da política indigenista no governo da Bahia ao longo da gestão de Jacques Wagner (20062013), buscando caracterizar o seu modelo institucional, bem como os condicionantes desse modelo sobre a interação dos atores políticos. Os dois autores, Carlos Rafael da Silva e Jessica Torres Costa e Silva, operam um deslocamento do campo da etnologia indígena para o da ciência política e utilizam as reflexões que veem desenvolvendo, há já certo tempo, no interior do movimento indígena, como atores indígenas e acadêmicos, nas pesquisas que apoiam os dois artigos.

A Constituição de 1988, ao introduzir novos preceitos constitucionais relativamente aos povos indígenas (respeito à organização social, costumes, línguas, crenças e tradições indígenas, asim como aos processos próprios de aprendizagem no ensino básico, entre outros), reconheceu-lhes o direito ao exercício da sua diferença étnica e instaurou novos marcos para as suas relações com o Estado e a sociedade brasileira. Parecia, pois, anunciar-se um novo tempo, no qual a sua consideração como uma categoria social transitória e as relações assimétricas que, até então, presidiam a sua comunicação com o estado e a sociedade brasileiros seriam substituídas por relações menos assimétricas e pelo reconhecimento da sua cidadania brasileira (o pleno exercício dos direitos civis e políticos que em face da legislação lhes couberem), preservadas as características culturais que os distinguem da sociedade nacional (indivíduos de origem e ascendência pré-colombiana que se identificam e são identificados como pertencentes a distintos grupos étnicos).

No estado da Bahia, a partir de 2006, a ascensão de Jacques Wagner ao cargo de governador suscitou ente os Índios a mesma expectativa positiva: tratar-se-ia de um aliado que acolheria as demandas indígenas e as incluiria na pauta de governo. Seis anos passados, e não obstante o reconhecimento de que "a temática indigenista pass[ou] a compor o cenário político de forma mais significativa”, a pesquisa desenvolvida por Jessica Costa e Silva constata não haver, de fato, uma política estadual para povos indígenas, mas tão somente transversalização da temática indígena nas ações setoriais do estado.

Tais ações, por sua vez, permanecem ao sabor do empenho individual de políticos e burocratas e, notadamente, das pressões dos líderes e dos agentes indígenas mais comprometidos.

4 Barbara Myerhoff (1979) define como "cerimônias definitórias" um tipo de "auto-biografia" coletiva, "um meio pelo qual um grupo cria sua identidade ao contar para si uma história sobre si mesmo, um processo ao longo do qual ganha vida a sua "Identidade Determinada e Definida"(...) (Turner, 2005, p. 182). Já no drama social de Turner, no sentido diltheyniano, "o significado é engendrado pela articulação de problemas presentes a um rico passado étnico, que então é infundido nos "feitos e provações" (frase de Dewey) da comunidade local. Alguns dramas sociais podem ser mais definitórios do que outros, isso é certo, mas muitos dramas sociais contêm, mesmo que apenas implicitamente, meios de reflexividade pública em seus processos reparadores. Ao ativá-los, os grupos avaliam a sua situação atual: a natureza e a força de seus laços sociais, o poder de seus símbolos, a eficácia de seus controles morais e legais, a sacralidade de suas tradições religiosas, e assim por diante (Turner, 2005, p. 182-183). 
A letra da lei não alterou a posição histórica da questão indígena no aparelho governamental como algo residual, como o comprovam o desconhecimento quase generalizado da legislação específica e da especificidade dos povos indígenas no estado da Bahia, do que decorrem, quase automaticamente, questionamentos quanto a lhes assegurar um tratamento diferenciado.

Do mesmo modo, o novo modelo de gestão definido como Território Etnoeducacional e analisado por Carlos Rafael Silva, ressente-se de inúmeros problemas de implementação que comprometem, gravemente, o projeto de educação intercultural na Bahia. O Projeto Observatório da Educação Escolar Indígena, que desde o ano de 2010 realiza o diagnóstico da situação educacional dos povos indígenas, e no qual Jessica e Carlos Rafael atuam como pesquisadores, evidenciou tais problemas e uma significativa defasagem entre a legislação sobre educação escolar indígena e o seu efetivo cumprimento. Mas uma vez evidencia-se o que parece incontornável: legislações mal aplicadas ou não aplicadas! O vácuo que daí resulta suscita, por sua vez, "um forte protagonismo político de indivíduos e organizações indígenas e de parceiros desses atores".

De acordo com o modelo analítico de Charles Lindblom (1981), Carlos Rafael supõe que a inadequação entre a legislação e o resultado final da política é passível de ser explicada pelos processos de implementação, que estão negativamente condicionados pelo regime de colaboração instaurado entre os agentes institucionais do sistema federativo brasileiro.

Os cinco textos parecem evidenciar, ou sugerir, a partir de distintos ângulos e enfoques, que o protagonismo e a criatividade indígenas, além do seu caráter volitivo, em geral de caráter individual, mas inelutavelmente reportado ao coletivo, preenche um espaço requerido pelas relações entre os povos indígenas, o estado e a sociedade brasileiros, frequentemente marcadas pelo tratamento -- social e institucional -- residual, que é concedido aos primeiros. Formalmente cidadãos plenos são, efetivamente, considerados, e tratados, como cidadãos sob condição. Talvez o cerne da questão resida na superação da própria noção limitada e etnocêntrica de cidadania, entendida como direitos e deveres comuns de indivíduos que partilham dos mesmos símbolos e valores nacionais (Ramos, 1991).

Os avanços formalmente assegurados pelo texto constitucional de 1988 dificilmente se concretizam em práticas e representações menos assimétricas, demandando a permanente vigilância dos Índios em relação aos direitos que eles conquistaram, mediante grande mobilização na Assembleia Nacional Constituinte.

Presentemente, forças contrárias tornam-se crescentemente poderosas, configurando o que tem sido denominado como "uma onda ou campanha anti-indígena", que tem se desdobrado em um conjunto significativo de propostas de emenda à constituição (PEC) e projetos de lei (PL), entre os quais se destaca a PEC 215 que propõe transferir do Poder Executivo para o Congresso Nacional a demarcação e homologação de terras indígenas e quilombolas, além de rever os territórios com processo fundiário e antropológico encerrado e publicado. 


\section{REFERÊNCIAS BIBLIOGRÁFICAS}

Danto, Arthur. "Artifact and Art", in Art/Artifact: African Art in Anthropology Collections. Exhibition Catalogue. New York: Center for African Art and Prestel Verlag.

Dawsey, John C. Victor Turner e a Antropologia da Experiência. Cadernos de Campo No. 13: 163-176, 2005.

Due, Berete. "Artefatos brasileiros no Kunstkammer Real", in Barbara Berlowicz, Beret Due, Peter Pentz e Esper Waehle (eds), Albert Eckhout volta ao Brasil 1644-2002, Nationalmuseet, Copenhagen, pp. 187-195.

Ferreira, Felipe Vander Velden. As Galinhas Incontáveis. Tupis, Europeus e Aves Domésticas na Conquista no Brasil. Journal de La Societé des Américanistes 2012, 98-2, pp. 97-140.

Foucault, Michel. Microfísica do poder. Organização, introdução e revisão técnica de Roberto Machado. 6a . edição, Rio de Janeiro: Graal, 1986.

Gell, Alfred. Vogel's Net: Traps as Artworks and Artworks as Traps. Journal of Material Culture. Sage Publications, Vol.1 (1) 1996: 15-38.

Lindblom, Charles Edward. O processo de decisão politica. Tradução Sérgio Bath. Brasília: Editora Universidade de Brasília, 1981.

Métraux, Alfred. À propos de deux objets Tupinambá du musée d'Ethnographie du Trocadéro, Bulletin Du Musée d'Ethnographie du Trocadéro, 2, pp. 3-18.

Pedreira, Hugo Prudente da Silva. "SaberAndar": Refazendo o Território Pataxó em Aldeia Velha. Monografia apresentada ao Departamento de Antropologia e Etnologia, FFCH da UFBA para obtenção do grau de Bacharel em Ciências Sociais/Concentração em Antropologia, 2013.

Ramos, Alcida. Os direitos do índio no Brasil na encruzilhada da cidadania. Série Antropológica No. 116, Universidade de Brasília: Departamento de Antropologia, 1991.

Sztutman, Renato. O Profeta e o Principal. A ação política ameríndia e seus personagens. São Paulo: Serviço de Comunicação Social. FFLCH/USP, 2008.

Turner, Victor. Dewey, Dilthey e Drama: um ensaio em Antropologia da Experiência (primeira parte) De Victor Turner (Dewey, Dilthey, and Drama: An Essay in the Anthropology of Experience". Cadernos de Campo No. 13: 177-185, 2005 (tradução de Herbert Rodrigues e revisão de John C. Dawsey). 